\title{
Effects of the quaternary ammonium compound QX-572 on ventricular tachyarrhythmias complicating acute myocardial infarction
}

\author{
L. Rydén, A. Hjalmarson, and A. Waldenström \\ From Division of Cardiology, Department of Medicine I, Sahlgren's Hospital, S-4I 345 Göteborg, Sweden
}

Patients with acute myocardial infarction who developed defined ventricular tachyarrhythmias were randomly allocated to two groups. The patients $(n=34)$ in one of the groups received the quaternary ammonium compound $N, N$-bis (phenylcarbamoylmethyl) dimethylammoniumchloride $(Q X-572)$ intravenously as an infusion of $8 \mathrm{mg} / \mathrm{kg}$ body weight over 30 minutes. The patients in the other group $(n=33)$ received saline and acted as controls. The analysis of arrhythmias was based on a continuous electrocardiogram recorded in parallel to routine monitoring during the 24 hours after the start of infusion. Only the detection of ventricular tachycardia or the development of ventricular fibrillation on routine monitoring could induce a change in antiarrhythmic treatment. The incidence of patients with ventricular tachycardia recorded was significantly lower in the $Q X-572$ group (38\%) than in the control group ( $73 \%)$. About half the number of patients with ventricular tachycardia recorded on the continuous electrocardiogram were also detected by means of routine monitoring. The number of patients with various types of ventricular premature contractions $(I-5 / \mathrm{min},>5 / \mathrm{min}$, paired, multifocal, $R$ on $T$ ), ventricular tachycardia, and rapid idioventricular rhythm were compared within successive one-hour periods. For all types of ventricular tachyarrhythmias except rapid idioventricular rhythm there was a lower incidence of arrhythmias in the $Q X-572$ group. A reduction was found also in the total number of observed I-minute intervals containing the various ventricular tachyarrhythmias. The difference between the groups remained for at least 16 hours, indicating a long duration of action after a single infusion of $Q X-572$. The first hour was also analysed in successive 5-minute periods and it was demonstrated that the effect of $Q X-572$ started after 5 minutes and was fully developed after 15 minutes. Of 26 patients with ventricular tachycardia detected on monitoring, 13 received $Q X-572(8 \mathrm{mg} / \mathrm{kg}$ body weight) and 13 lignocaine ( 75 $\mathrm{mg}$ ) as an intravenous bolus followed by an infusion of $4 \mathrm{mg} / \mathrm{min})$. The number of patients developing further runs of ventricular tachycardia did not differ between the $Q X-572(6)$ and the lignocaine (8) groups.

$Q X-572$ caused an increase in heart rate maximal at the end of infusion (mean increase $\pm S E=30 \pm 3$ beats/min). Systolic and diastolic blood pressures increased after the completion of infusion and the maximal systolic increase $\pm S E$ was $23 \pm 3 \mathrm{mmHg}$, while the increase in diastolic pressure was $12 \pm 2 \mathrm{mmHg}$. During administration of $Q X-572$ some patients had a drop in blood pressure causing a temporary interruption of the infusion. Careful observations were made of side effects of $Q X-572$. The most common was circumoral paraesthesia experienced at the end of the infusion. It is concluded that $Q X-572$ is an effective agent against ventricular tachyarrhythmias complicating acute myocardial infarction. The increase in heart rate and late rise of blood pressure are clinically the most important drawbacks. $Q X-572$ is considered to be a valuable antiarrhythmic drug but at present it should be used only for defined critera such as refractory ventricular arrhythmias.

The quaternary ammonium compound and lignocaine derivative $\mathrm{N}, \mathrm{N}$-bis (phenylcarbamoylmethyl) dimethylammoniumchloride (QX-572) can effectively abolish experimentally induced supraventricReceived 1o September 1974 . ular and ventricular arrhythmias in animals (D'Amato and Truant, 1962; Covino and Rachwall, 1964; Katz, I964; Madan, Khanna, and Madan, 1967). In man ventricular tachyarrhythmias occurring during general anaesthesia and various cardiac 
disorders were abolished by QX-572 (Katz, 1965; Schwartz, Stapleton, and Covino, 1967). When $\mathrm{QX}-572,8 \mathrm{mg} / \mathrm{kg}$ body weight, was given to $\mathrm{I2}$ patients with serious ventricular tachyarrhythmias including recurrent ventricular fibrillation refractory to other antiarrhythmic drugs, the arrhythmias vanished in almost all patients (Rydén et al., I974b). In these studies QX-572 seemed to have a rapid onset and a long duration of action. However, other factors such as the previous administration of antiarrhythmic drugs, incomplete detection of arrhythmias, and the lack of suitable controls may have influenced the results.

The present investigation was planned to provide a more thorough appraisal of QX-572. By comparing a treatment and a control group, it was aimed to assess not only its antiarrhythmic effect but also the time of onset and duration of action of the drug, and any side effects which may result from its use.

\section{Subjects and methods}

Patients admitted to the coronary care unit (CCU) with proven or suspected acute myocardial infarction were considered for the study if they developed ventricular tachyarrhythmias of one or more of the following types: I) $>5$ ventricular premature contractions per minute; 2 ) paired ventricular premature contractions; 3) multifocal ventricular premature contractions; 4) $R$ on $T$ ventricular premature contractions; and 5) ventricular tachycardia defined as 3 or more ventricular premature contractions in sequence at a rate exceeding 100 a minute. Patients with second- or third-degree atrioventricular block, right and left bundle-branch block, or atrial fibrillation or flutter were excluded. Arrhythmia detection and electrocardiographic interpretation were performed by means of the routine monitoring in the coronary care unit supplemented by a 12-lead electrocardiogram when necessary for accurate diagnosis. Conventional criteria were used for the definition of arrhythmias and conduction disturbances (Goldman, 1970). The presence of frank pulmonary oedema or hypotension (systolic blood pressure below $90 \mathrm{mmHg}(12 \mathrm{kPa})$ ) excluded the patient from the study as did antiarrhythmic treatment instituted before admission to the coronary care unit. The patients accepted for the study were randomly allocated to either a QX-572 group or a control group. QX-572 (Astra, Södertälje, Sweden) in a total dose of $8 \mathrm{mg} / \mathrm{kg}$ body weight was infused as a 0.5 per cent solution in saline over 30 minutes. The patients in the control group received the corresponding volume of saline. The infusions were given by means of an infusion pump (Infusomat, Braun, Melsungen, West Germany) into an arm vein. Informed consent to drug infusion was obtained from the patients before randomization.

Except for the administration of antiarrhythmic drugs, the patients were managed according to the routine of the coronary care unit (Henning and Holmberg, 1971). Monitoring was continued throughout the study and judgement concerning further antiarrhythmic treatment was based on this routine arrhythmia-detecting system. After the start of the initial drug infusion no further antiarrhythmic treatment was permitted for 15 minutes unless ventricular fibrillation occurred. Thereafter, the detection of ventricular tachycardia was accepted as an indication for a change in treatment. The patients originally on QX-572 then received lignocaine (Xylocain $^{\mathrm{R}}$, Astra, Södertälje, Sweden). An intravenous bolus injection of $75 \mathrm{mg}$ over 2 minutes was immediately followed by an infusion of $4 \mathrm{mg} / \mathrm{min}$ by means of an infusion pump (Perfusor, Braun, Melsungen, West Germany). The infusion rate could be reduced if suspicions of side effects occurred. The patients in the saline group were at this stage randomly given either QX-572 or lignocaine. The dosages and modes of administration of the drugs were as described. If ventricular tachycardia was detected once more and I5 minutes had passed after the last administration of drug, patients on QX-572 received lignocaine. Patients already on this drug were treated without any predetermined rules and so were patients developing ventricular fibrillation, irrespective of when it occurred. If persistent hypotension, pulmonary oedema, atrioventricular block of second or third degree, bundle-branch block, atrial flutter, or atrial fibrillation were detected treatment was given as appropriate.

The monitored electrocardiograph was also continuously recorded using an ink-writing recorder (Mingograf 8I, Siemens-Elema AB, Stockholm, Sweden), with a paper speed of $10 \mathrm{~mm} / \mathrm{s}$. The recording was always continued for 24 hours from the start of the first drug. The time of drug administration and other interventions were recorded. All data concerning the occurrence of ventricular tachyarrhythmias were derived from the continuous electrocardiogram. This method of arrhythmia detection has previously been described in detail by Mogensen (1970). The electrocardiogram from each patient was analysed minute by minute. A I-minute interval was accepted only if every QRS complex could be identified. Then the accepted I-minute intervals were classified with regard to the presence or absence of ventricular arrhythmias according to the following criteria.

I) Ventricular premature contraction $=\mathbf{a} Q R S$ complex with a duration $>0.10 \mathrm{~s}$ and a configuration differing from that of the basic QRS complex. It should not be preceded by a premature $P$ wave. If present, the contractions were subgrouped as follows: a) I to $5 / \mathrm{min}$; b) $>$ $5 / \mathrm{min} ; \mathrm{c})$ all $=\mathrm{a}+\mathrm{b} ; \mathrm{d})$ monofocal $=\mathrm{QRS}$ complexes of only one type; e) multifocal $=\mathrm{QRS}$ complexes of at least two configurations within a I-minute interval; $f$ ) paired $=$ two ventricular premature contractions in sequence; g) $\mathrm{R}$ on $\mathrm{T}=$ ventricular premature contractions starting within 85 per cent of the QT time of the preceding QRS complex.

2) Ventricular tachycardia $=$ runs of $>3$ ventricular premature contractions in sequence with a QRS rate exceeding $100 / \mathrm{min}$. To be accepted as ventricular tachycardia there should not be any suspicion of a supraventricular tachycardia with aberrant conduction.

3) Ventricular fibrillation = rapid and irregular oscillations of the baseline. 
4) Rapid idioventricular rhythm $=$ runs of $\geq 3$ ventricular premature contractions: at a rate below $100 / \mathrm{min}$.

5) Ventricular asystole $=a \mathrm{RR}$-interval $\geq 3 \mathrm{~s}$.

After the classification of the I-minute intervals the information obtained was compiled into I-hour long periods, and also into 5-minute long periods during the first hour after drug administration. A comparison was made of the overall incidence of ventricular tachycardia in the different groups of patients, as well as the number of I-hour and 5-minute periods containing ventricular tachyarrhythmias. Finally, the percentage of I-minute intervals containing various types of ventricular tachyarrhythmias were compared between the groups. In addition the content of supraventricular tachyarrhythmias, bundle-branch block, and atrioventricular block were appraised for each I-hour or 5-minute period.

Heart rate and brachial artery pressure (by cuff) were measured before the start of the infusion, every ro minutes during the first hour, and afterwards at 90 and 150 minutes. Thereafter these measurements were performed according to usual routine. Venous blood samples were taken at $30,60,120$, and 240 minutes after the start of infusion and QX-572 in plasma was determined as described by Rydén, Berlin, and Treiber (r974a). Blood samples were also taken on the day of study and one and six days later for serum electrolytes and teits of renal and hepatic function.

To compare the clinical and laboratory findings in the two groups the following tests were used: Student's ttest for independent means, $\chi^{2}$-test, and Fisher's exact probability test for the test of independent proportions (large and small sample, respectively), and KolmogorovSmirnov's two-sample test for comparison of distributions. The mean changes in the laboratory assessments were compared between the groups using the following ratio, which for large samples is approximately distributed as the standard normal deviation:

$$
\frac{\mathrm{d}_{1}-\mathrm{d}_{2}}{\sqrt{\mathrm{SE}_{1}^{2}+\mathrm{SE}_{2}^{2}}}
$$

This test was also used to compare the mean changes in blood pressure and heart rate after the injections of QX-572 or saline. To test for antiarrhythmic effect either the $\chi^{2}$-test or Fisher's exact probability test was used depending on the size of the samples. Details of the test methods are given by Siegel (1956) and Snedecor and Cochran (1967).

\section{Results}

\section{Composition of patient material}

Altogether 98 patients were admitted to the study (Fig. I). Fifteen patients did not fulfil the World Health Organization (1970) criteria of acute myocardial infarction. Of the remaining 83 patients, 44 belonged to the QX-572 and 39 to the saline group. In the QX-572 group 8 patients entered the study with ventricular tachycardia. The corresponding number in the saline group was 6 . In 2 patients the QX-572 infusions were not completed. Accordingly, 34 patients remained in the QX-572 and 33

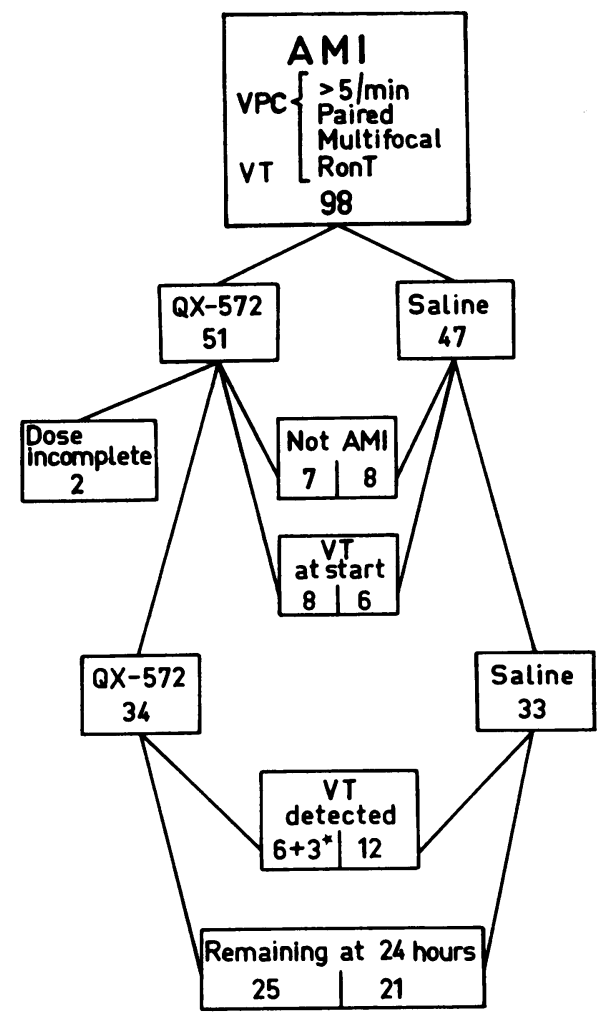

FIG. I Schematic presentation of the patient material illustrating the constitution of a $Q X-572$ and saline group with various subgroups.

* Indicates patients withdrawn because of ventricular tachycardia not subsequently proven by the continuous electrocardiogram.

patients in the saline group forming the basis for the comparative study. Some characteristics of the patients are presented in Table $\mathbf{I}$. The groups were also compared as regards the presence of hypertension, diabetes, and digitalis treatment, as well as heart rate and arterial blood pressure at start of therapy, and potassium, creatinine, and bilirubin in serum. Except that a history of angina pectoris lasting longer than one month was more common in the $Q X-572$ group $(P<0.01)$, no significant differences were found between the two groups. The distribution of patients by types of ventricular tachyarrhythmias constituting the reason for entering the study are shown in Table 2 . In some patients more than one type of arrhythmia was present.

In the QX-572 group 97.I per cent of the I-minute intervals were suitable for electrocardiographic analysis. The corresponding figure for the saline group was 96.6 per cent. 
TABLE I Some clinical and laboratory data in $Q X-572$ and saline groups of patients

\begin{tabular}{|c|c|c|c|}
\hline & $\begin{array}{l}Q X-572 \\
(n=34) \\
\text { No. }\end{array}$ & $\begin{array}{l}\text { Saline } \\
(n=33) \\
\text { No. }\end{array}$ & Difference \\
\hline \multicolumn{4}{|l|}{ Sex } \\
\hline Male & 29 & 28 & NS \\
\hline Female & 5 & 5 & \\
\hline \multicolumn{4}{|l|}{ Age } \\
\hline $30-39$ years & $\mathbf{I}$ & 0 & NS \\
\hline $40-49$ & 5 & 2 & \\
\hline $50-59$ & II & 20 & \\
\hline $60-69$ & 17 & II & \\
\hline \multicolumn{4}{|l|}{ Site of infarction } \\
\hline Anterior & 13 & 15 & NS \\
\hline Posterior & 14 & 15 & \\
\hline Uncertain & 7 & 3 & \\
\hline $\begin{array}{l}\text { Delay start symptoms - start infusion (hr) } \\
\quad(\text { Mean } \pm \text { SE })\end{array}$ & $\begin{array}{l}16 \pm 2.5 \\
(n=31)\end{array}$ & $\begin{array}{l}19 \pm 3.0 \\
(n=32)\end{array}$ & NS \\
\hline \multicolumn{4}{|l|}{ Previous infarction } \\
\hline 0 & 24 & 27 & NS \\
\hline $\mathbf{I}$ & 8 & 5 & \\
\hline$\geq 2$ & 2 & $\mathbf{r}$ & \\
\hline Angina > I month & I8 & 6 & $\mathbf{P}<0.01$ \\
\hline Previous heart failure & 7 & 3 & NS \\
\hline $\begin{array}{l}\text { Left heart failure day of study } \\
\text { SGOT* maximum units } 1 \text { (normal }<17)\end{array}$ & 4 & 3 & NS \\
\hline 517 & $\mathbf{I}$ & $\mathbf{I}$ & NS \\
\hline $\overrightarrow{18}-100$ & 17 & 17 & \\
\hline $10 I-200$ & 12 & Io & \\
\hline $\begin{array}{l}>200 \\
\text { Mean } \pm S E\end{array}$ & $\stackrel{4}{108} \pm 12$ & $\stackrel{3}{108} \pm 14$ & NS \\
\hline
\end{tabular}

^ Serum aspartate aminotransferase.

TABLE 2 Distribution of patients by type of ventricular tachyarrhythmia at start of study in $Q X-572$ and saline groups, respectively

\begin{tabular}{llll}
\hline $\begin{array}{l}\text { Type of ventricular } \\
\text { premature } \\
\text { contractions }\end{array}$ & $\begin{array}{l}Q X-572 \\
(n=34) \\
\text { No. }\end{array}$ & $\begin{array}{l}\text { Saline } \\
(n=33) \\
\text { No. }\end{array}$ & $\begin{array}{l}\text { Differ- } \\
\text { ence }\end{array}$ \\
\hline$>5 /$ min & 16 & 17 & NS \\
Paired & 10 & 5 & NS \\
Multifocal & 13 & 18 & NS \\
R on T & 0 & 0 & NS \\
& & & \\
\hline
\end{tabular}

\section{Effects on arrhythmias}

The number of patients in the two groups who had ventricular tachycardia recorded on the continuous electrocardiogram and the time of occurrence is shown in Fig. 2. After 24 hours, 13 patients (38\%) in the QX-572 and $24(73 \%)$ in the saline group had developed this arrhythmia. The lower incidence in the QX-572 group was statistically significant $(P<0.01)$. The total amount of $Q X-572$ administered to patients developing ventricular tachycardia (mean $\pm \mathrm{SE}=620 \pm 25 \mathrm{mg}$ ) did not differ significantly from the amount given to those who did not

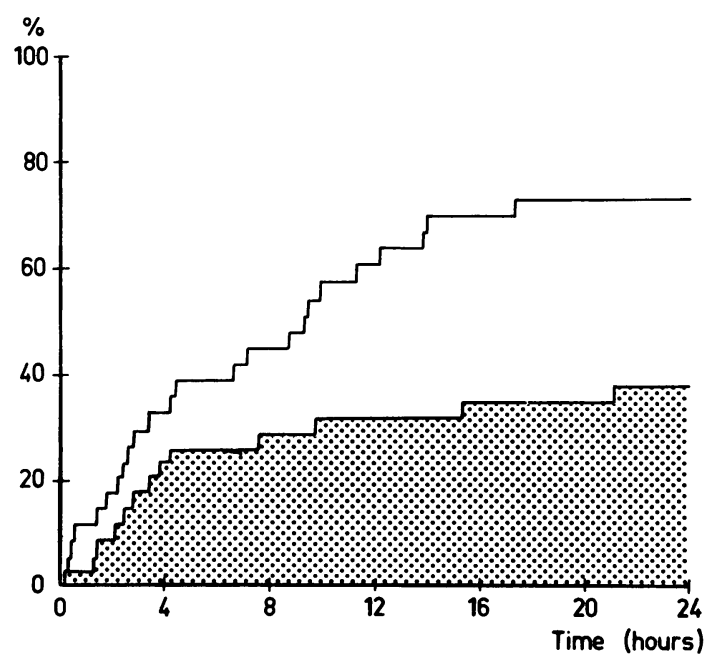

FIG. 2 Percentage of patients in the $Q X-572$ and saline groups with ventricular tachycardia recorded on the continuous electrocardiogram. The time of occurrence of arrhythmia is shown for the individual patients. In this and the following figures the $Q X-572$ group is identified by the dotted area. 
TABLE 3 Overall incidence of one-hour periods containing various types of ventricular tachyarrhythmias

\begin{tabular}{|c|c|c|c|c|c|}
\hline $\begin{array}{l}\text { Type of ventricular premature } \\
\text { contraction }\end{array}$ & $\begin{array}{l}Q X-572 \\
(n=67 I) \\
N o .\end{array}$ & $\%$ & $\begin{array}{l}\text { Saline } \\
(n=567) \\
\text { No. }\end{array}$ & $\%$ & Difference \\
\hline $\begin{array}{l}\text { I-5/min } \\
>5 / \mathrm{min} \\
\text { Paired } \\
\text { Multifocal } \\
\text { R on T } \\
\text { Rapid idioventricular rhythm } \\
\text { Ventricular tachycardia }\end{array}$ & $\begin{array}{r}372 \\
33 \\
37 \\
28 \\
1 \\
8 \\
13\end{array}$ & $\begin{array}{l}55 \\
5 \\
6 \\
4 \\
0.1 \\
1 \\
2\end{array}$ & $\begin{array}{r}441 \\
115 \\
136 \\
148 \\
18 \\
10 \\
43\end{array}$ & $\begin{array}{r}78 \\
20 \\
24 \\
26 \\
3 \\
2 \\
8\end{array}$ & $\begin{array}{l}P<0.001 \\
P<0.001 \\
P<0.001 \\
P<0.001 \\
P<0.001 \\
N S \\
P<0.001\end{array}$ \\
\hline
\end{tabular}
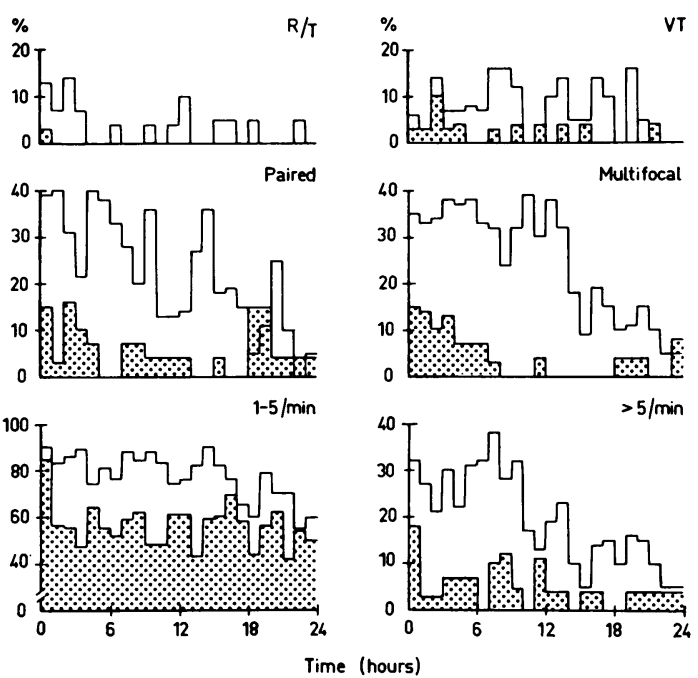

FIG. 3 Percentage of observed patients with $R$ on $T$ ventricular premature contractions, ventricular tachycardia, paired ventricular premature contractions, multifocal ventricular premature contractions and $I$ to 5 and more than 5 contractions/min within each consecutive I-hour period.

$(593 \pm 15 \mathrm{mg})$. Nor were there any significant differences in plasma levels of QX- 572 between patients with and those without ventricular tachycardia.

When comparing the incidence of one-hour and one-minute periods containing ventricular tachyarrhythmias, the patients remained in the respective groups until a change in therapy was instituted because of the detection of ventricular tachycardia on the routine monitors. Of the 24 saline patients with ventricular tachycardia, I2 were detected $(50 \%)$. The corresponding figure in the QX-572 group was 6 out of $13(46 \%)$. In addition 3 patients in the QX-572 group were falsely classified as having ventricular tachycardia caused by artefacts in 2 cases, and with no obvious reason in $\mathrm{I}$.

In the QX-572 group a total of 671 and in the saline group 567 one-hour periods were observed. For all types of ventricular tachyarrhythmias except rapid idioventricular rhythm there was a lower incidence $(\mathrm{P}<0.00 \mathrm{I})$ of one-hour periods with arrhythmias in the QX-572 group (Table 3). In Fig. 3 the number of patients with each of the different types of ventricular premature contractions are presented in consecutive one-hour periods. Except for rapid idioventricular rhythm the total number of one-minute intervals with the various types of ventricular tachyarrhythmias was less $(P<0.001)$ in the QX-572 compared with the saline group. As an example the proportion of oneminute intervals with $I$ to 5 and more than 5 ventricular premature contractions per minute for consecutive one-hour periods are presented in Fig. 4. The occurrence of ventricular arrhythmias remained lower in the QX-572 group throughout the major part of the 24-hour long period of observation (Fig. 3-4).

During the first hour of observation the incidence of ventricular tachyarrhythmias in the QX-572 group was reduced. The reduction was obvious after about 15 minutes. A small increase, to less than initial levels, was noted during the last 20 minutes of the hour. In the saline group the incidence of ventricular arrhythmias remained essentially stable during the first hour. The difference between the groups became statistically significant during the third 5-minute period (Fig. 5).

QX-572 was given to 13 patients and lignocaine to another 13 because of ventricular tachycardia. Of these patients 8 had originally been allocated to the QX-572 and 6 to the saline group. The remaining I2 were found to have ventricular tachycardia during the observation period after a saline infusion. The incidence of patients developing further episodes of ventricular tachycardia (Fig. 6) did not 

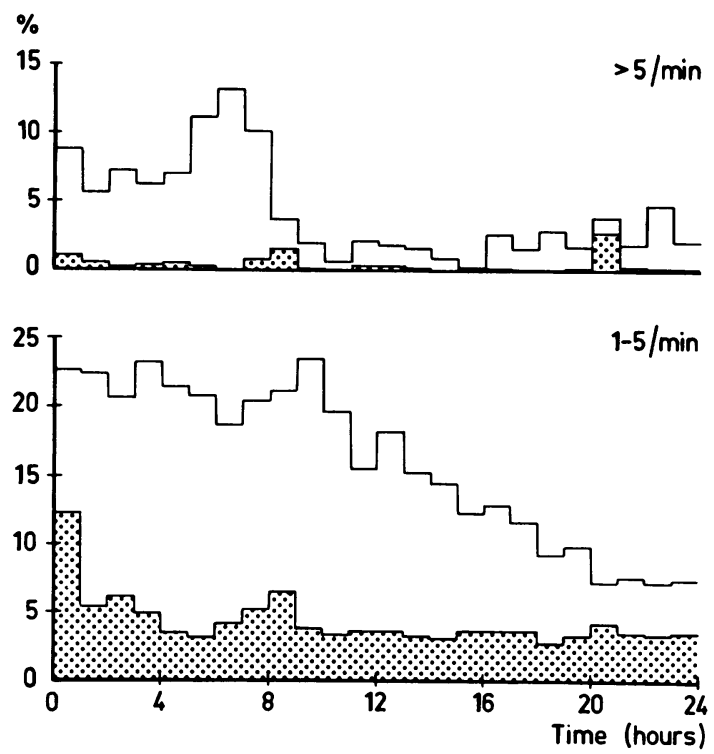

FIG. 4 Percentage of observed I-minute intervals with more than 5 ventricular premature contractions/ min and I to 5 ventricular premature contractions/ min during each consecutive I-hour period.

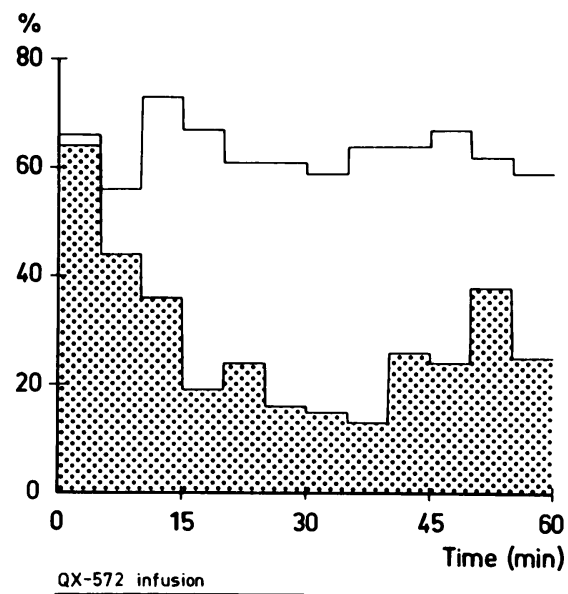

FIG. 5 The incidence of any type of ventricular tachyarrhythmia within each consecutive 5-minute period during the first hour following the start of $Q X-572$ and saline infusion, respectively.

differ significantly between QX-572 and lignocaine. In 3 cases the rate of lignocaine infusion was reduced because of side-effects (hypotension, impaired consciousness, and dizziness, respectively). Lignocaine was administered to the 6 patients from the QX-572 group who were found to have ventricular

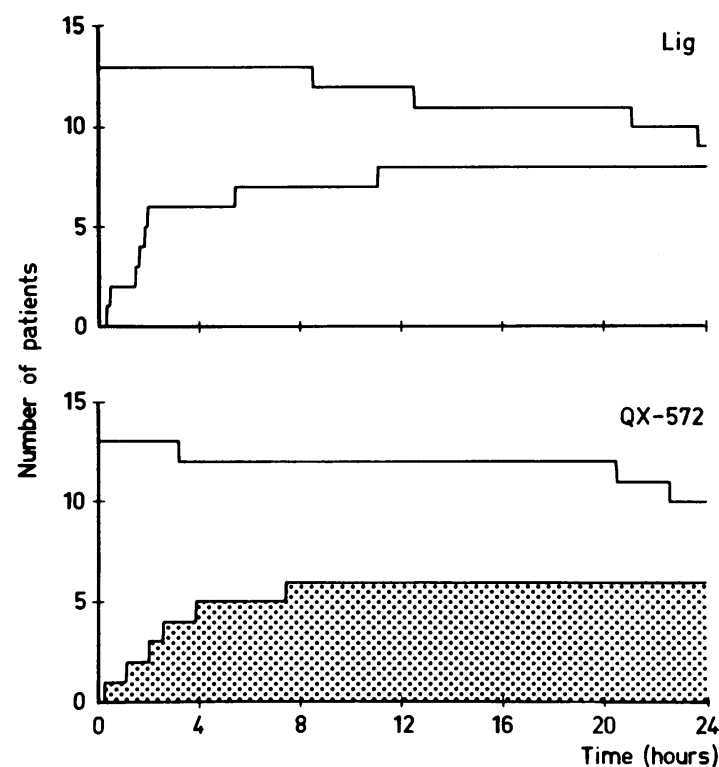

FIG. 6 Number of patients treated with $Q X-572$ (lower panel) and lignocaine (Lig; upper panel) in whom ventricular tachycardia relapsed. The time of occurrence is shown for individual patients. The upper line shows the length of the observation period for patients who did not develop further episodes of ventricular tachycardia. Lig = lignocaine.

tachycardia. Of these, 4 developed further runs of ventricular tachycardia.

Four of the 98 patients suffered ventricular fibrillation. Two of those patients belonged to the saline group. In both, QX-572 infusion had been started after the detection of ventricular tachycardia and before the onset of ventricular fibrillation. In I case QX-572 infusion only lasted for 6 minutes before the start of ventricular fibrillation. After DC-conversion and discontinuation of QX572 this patient was given lignocaine. Further attacks of ventricular fibrillation were treated with several antiarrhythmic agents and the patient survived. The second patient had ventricular fibrillation in connexion with cardiac rupture $\mathrm{I}$ hour and 8 minutes after the start of the QX-572 infusion. The 2 patients in the QX-572 group who developed ventricular fibrillation had previously been found to have ventricular tachycardia; ventricular fibrillation occurred after the initiation of lignocaine.

The incidence of supraventricular arrhythmias was low in both the QX-572 and the saline group. In addition to some supraventricular premature beats occasional short runs of ectopic atrial tachy- 
arrhythmias were observed without any preponderance for either group.

\section{Effects on blood pressure, heart rate, and lab- oratory findings}

QX-572 caused an increase in heart rate only ro minutes after the start of infusion, which was maximal (mean $\pm S E=30 \pm 3$ beats $/ \mathrm{min}$ ) at the end of the infusion and still significant $(P<0.001) 60$ minutes after the completion of the infusion. The systolic and diastolic blood pressure increased from Io minutes after the end of the infusion of drug $(P<0.01)$. The increase was maximal Io minutes later (mean systolic $\pm \mathrm{SE}=23 \pm 3 \mathrm{mmHg}$ (3.1 \pm $0.4 \mathrm{kPa}$ ); mean diastolic $\pm \mathrm{SE}=\mathrm{I} 2 \pm 2 \mathrm{mmHg}$ $(\mathrm{I} .6 \pm 0.3 \mathrm{kPa}) ; \quad \mathrm{P}<0.00 \mathrm{I})$ and still significant $(P<0.01)$ at the observation 60 minutes after the completion of infusion (Fig. 7). The comparison of laboratory findings in the groups of patients did not reveal any untoward effects of QX-572.

\section{Side-effects}

The side-effects of all 58 patients receiving QX572 have been considered. Of these patients, $5 \mathrm{I}$ constituted the original QX-572 group (Fig. I) and 7 were given QX-572 because of ventricular tachycardia. One received QX-572 for only 6 minutes (without any side-effects) before the onset of ventricular fibrillation causing a subsequent change in therapy. This patient has been omitted from further evaluation. The saline group consists, as regards the occurrence of side-effects, of 40 patients. These were the original 47 reduced by the 7 who were later given $Q X-572$. In both groups some patients also received lignocaine.

There were only few and unimportant conduction disturbances and periods of asystole without any differences between the groups. Subjective sideeffects of various types were reported by patients receiving QX-572 (Table 4). The most common $(25 \%)$ was circumoral paraesthesia, often combined with numbness of the tongue. This usually started I5 to 20 minutes after the start of QX-572 infusion and lasted until about 15 minutes after completion of drug administration. Chest pain (12\%) was the next most common subjective side-effect and

TABLE 4 Subjective side-effects reported by patients receiving $Q X-572$

\begin{tabular}{llr}
\hline Type of side-effect & $\begin{array}{l}Q X-572 \\
(n=57)\end{array}$ & \\
& $N o$. & $\%$ \\
\hline No side-effects & 30 & 53 \\
Side-effects & & \\
Circumoral paraesthesia & I4 & 25 \\
Paraesthesia in infusion arm & I & 2 \\
Nausea & 5 & 9 \\
Dizziness & $\mathrm{I}$ & 2 \\
Dyspnoea & $\mathrm{I}$ & 2 \\
Chest pain & 7 & 12 \\
Palpitation & 3 & 5 \\
& & \\
\hline
\end{tabular}

FIG. 7 Heart rate and blood pressure before and after the infusion of $Q X-572$ (filled symbols) and saline (unfilled symbols), respectively. The figure presents mean levels $\pm S E . \Delta=$ heart rate; $\bigcirc=$ systolic blood pressure; $\square=$ diastolic blood pressure. 
TABLE 5 Number of patients receiving analgesic and/or anti-emetic drugs between 0 and 3 , and between 3 and 24 hours after start of study

\begin{tabular}{|c|c|c|c|c|c|c|}
\hline $\begin{array}{l}\text { Time } \\
(h r)\end{array}$ & Type of drug & $\begin{array}{l}Q X-572 \\
\text { No. }\end{array}$ & $\%$ & $\begin{array}{l}\text { Saline } \\
\text { No. }\end{array}$ & $\%$ & Difference \\
\hline \multirow{3}{*}{$0-3$} & & \multicolumn{2}{|l|}{$\mathrm{n}=55^{\star}$} & \multicolumn{2}{|c|}{$\mathrm{n}=3^{\star} 8^{\star}$} & \\
\hline & Analgesic & 17 & $3 I$ & 14 & 37 & NS \\
\hline & Anti-emetic & 6 & II & 3 & 8 & NS \\
\hline \multirow{3}{*}{$3-24$} & & $\mathrm{n}=53^{\star}$ & & \multicolumn{2}{|c|}{$\mathrm{n}=34^{\star}$} & \\
\hline & Analgesic & 12 & 23 & II & 32 & NS \\
\hline & Anti-emetic & 8 & 15 & I & 3 & NS \\
\hline
\end{tabular}

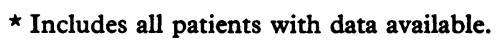

TABLE 6 Patients who died during period of investigation or later during stay in hospital

\begin{tabular}{|c|c|c|c|c|c|}
\hline \multirow{2}{*}{$\begin{array}{l}\text { Case } \\
\text { No. } \\
14\end{array}$} & \multirow{2}{*}{$\begin{array}{l}\text { Time start } \\
\text { of study } \\
\text { to death }\end{array}$} & \multirow{2}{*}{$\begin{array}{l}\text { Cause of death } \\
\text { Cardiac rupture }\end{array}$} & \multirow{2}{*}{$\begin{array}{l}\text { Necropsy findings } \\
\begin{array}{c}\text { Extensive anteroseptal acute } \\
\text { myocardial infarction }\end{array}\end{array}$} & \multicolumn{2}{|c|}{ Drugs during study } \\
\hline & & & & I) saline & 2) $Q X-572$ \\
\hline 56 & $14 \frac{1}{2} \mathrm{hr}$ & Cardiogenic shock & $\begin{array}{l}\text { Extensive anteroseptal acute } \\
\text { myocardial infarction; rupture of } \\
\text { interventricular septum }\end{array}$ & I) saline & 2) lignocaine \\
\hline 60 & IO dy & Cardiac rupture & $\begin{array}{l}\text { Posterolateral acute myocardial } \\
\text { infarction }\end{array}$ & saline & \\
\hline 47 & II dy & $\begin{array}{l}\text { Sudden death } \\
\text { (asystole) }\end{array}$ & $\begin{array}{l}\text { Extensive posterolateral acute } \\
\text { myocardial infarction }\end{array}$ & saline & \\
\hline I7 & $16 \mathrm{dy}$ & Cardiac insufficiency & $\begin{array}{l}\text { Extensive anterolateral and septal } \\
\text { acute myocardial infarction }\end{array}$ & I) saline & 2) $Q X-572$ \\
\hline 26 & $21 \mathrm{dy}$ & Cardiac insufficiency & $\begin{array}{l}\text { Extensive anterolateral and septal } \\
\text { acute myocardial infarction, } \\
\text { left ventricular aneurysm }\end{array}$ & 1) $Q X-572$ & 2) lignocaine \\
\hline
\end{tabular}

was usually experienced at the end of the infusion period. Chest pain caused the withdrawal of one patient from the study after 14 minutes of infusion. In one other case the QX-572 infusion was interrupted but subsequently completed without further problems. Five patients $(9 \%)$ complained of nausea during the infusion of QX-572. In one of these the drug infusion was stopped after ro minutes. In the remaining 4 the infusion was completed. Chest pain and nausea also occurred during and after the infusion of saline but were not reported as side-effects by the nurses. Table 5 presents a comparison between the QX-572 and saline groups regarding the number of patients who received analgesic injections and anti-emetic drugs. Neither during the first 3 hours of observation nor during the remainder of the observation period were there any significant differences. A decrease in systolic blood pressure to a level below $99 \mathrm{mmHg}$ (I2.0 $\mathrm{kPa}$ ) caused interruption of QX-572 infusion in 4 patients $(7 \%)$; the infusion was, however, completed without further complications in all cases. In one patient QX-572 infusion was temporarily delayed because of the heart rate exceeding 150/min.

Of the 98 patients admitted to the study, 2 died during the period of observation and 4 later during the stay in hospital. One patient belonged to the QX-572 and 5 to the saline group. Data concerning these patients are presented in Table 6 . In no case could death be related to any of the drugs used in the investigation.

\section{Discussion}

\section{Patient selection and design of study}

Ventricular tachyarrhythmias complicating acute myocardial infarction seem to be the most important indication for QX-572. Patients presenting this problem were, therefore, chosen for the evaluation 
of the properties of the drug. In this type of patient the clinical condition and the incidence of ventricular tachyarrhythmias changes from one time to another. Thus, conclusions concerning the influence of an antiarrhythmic agent can be drawn only after comparison with an appropriate control group. The saline and QX-572 groups were comparable in all respects except for the history of angina pectoris. This dissimilarity cannot reasonably explain the difference in the occurrence of ventricular tachyarrhythmias.

The study was not performed as a double-blind trial. Knowledge of actual treatment was considered important in case of emergency. Also it was known that the administration of QX-572 would be apparent because of an increase in heart rate soon after the start of the infusion (Rydén et al., 1974b). The single-blind design could not introduce any bias with reference to the final detection of ventricular tachyarrhythmias. This was based on continuous electrocardiographic recording interpreted according to defined criteria. The detection rate was comparable to that previously found in the coronary care unit (Rydén, Holmberg, and Waldenström, r974c).

Arrhythmia detection by nurses is not satisfactory for scientific purposes (Mogensen, 1970; Romhilt et al., 1973; Rydén et al., 1974c). Intermittent sampling of the electrocardiogram has been widely used for the evaluation of antiarrhythmic efficacy but allows erroneous conclusions to be drawn (Rydén, Waldenström, and Holmberg, 1974d). In the present study the results were, therefore, based on the interpretation of continuous electrocardiographic recordings.

Patients were admitted to the study according to the criteria suggested by Lown et al. (1967) as indications for treatment of ventricular arrhythmias in acute myocardial infarction. Under carefully controlled conditions it has been shown possible to delay the institution of antiarrhythmic treatment until the development of ventricular tachycardia (Mogensen, 1970). In the present study the detection of ventricular tachycardia led to a change of therapy. This implies successive withdrawal of patients with a specific type of arrhythmia. Keeping this limitation in mind, it is still possible to draw conclusions from the comparative study. It is important that the rate of withdrawal was relatively low and proportional in the two groups.

\section{Antiarrhythmic efficacy}

The QX-572 and saline groups were compared in different ways as regards the presence of ventricular tachyarrhythmias. In all respects QX-572 turned out to be an effective antiarrhythmic agent and the present study clearly confirms previous experience with the drug (Katz, 1965; Schwartz et al., 1967; Rydén et al., 1974b). QX-572 is not only effective in the overall reduction of ventricular tachyarrhythmias but also diminishes the occurrence of individual types of ventricular premature contractions (Fig. 3). Of interest is the extremely low incidence of $R$ on $T$ ventricular premature contractions in the QX-572 group. This type of arrhythmia has been found to be especially ominous as a precursor of ventricular fibrillation in man (Mogensen, 1970; Dhurandhar, MacMillan, and Brown, 197I). In a recent experimental study on baboons (Bruyneel and Opie, 1973) it was found that ventricular tachycardia, ventricular bigeminy, and $R$ on $T$ ventricular premature contractions were the three types of ventricular tachyarrhythmias correlated to later ventricular fibrillation. The only type of ventricular tachyarrhythmia which was not reduced by QX$\mathbf{5 7 2}$ was rapid idioventricular rhythm. This arrhythmia has been described as relatively benign and not by itself necessitating the initiation of antiarrhythmic treatment (Rothfeld et al., 1968; Norris, Mercer, and Yeates, 1970). Lignocaine has also been shown to be ineffective against rapid idioventricular rhythm (Mogensen, 1970).

\section{Onset and duration of action}

The onset of action is rapid, starting after $5 \mathrm{~min}$ utes (Fig. 5). A limited recurrence of ventricular tachyarrhythmias was noted 40 minutes after the start of infusion of QX-572. Contrary to previous statements (Rydén et al., 1974b), this observation supports the hypothesis that the initial antiarrhythmic effect of QX-572 is in some way linked to the drug-induced increase in heart rate. Treatment of ventricular tachyarrhythmias by means of increase of heart rate was originally described by Swedberg and Malm (1964) and Sowton, Leatham, and Carson (1964). This explanation for the antiarrhythmic properties is not applicable after the initial period when the effect remains despite the heart rate returning to normal.

The results indicate that the suppression of ventricular tachyarrhythmias, caused by a single infusion of QX-572, remains for a long period of time. This is in accordance with previous findings (Schwartz et al., 1967; Rydén et al., 1974b). It is difficult to establish the exact duration. The diminishing difference between the groups seems to be caused by a reduction of the incidence in the saline group rather than an increase in the QX-572 group. However, a significant difference in the occurrence of ventricular tachyarrhythmias still remains after as long as 16 hours (Fig. 3 and 4). A proportionately large number of QX-572 patients was found 
to have ventricular tachycardia during the first 4 hours after the infusion (Fig. 2). This does not contradict a long duration of action. A reduced incidence of ventricular tachycardia is only one of several criteria of antiarrhythmic efficacy. This initial accumulation of patients with ventricular tachycardia may reflect a therapeutic failure of the amount of QX-572 used or of the drug as such rather than a decline in effect. The reasons for the apparently long duration of action of QX-572 are open to discussion. It may reflect a spontaneous reduction in the incidence of ventricular tachyarrhythmias caused by an early reduction of ventricular premature contractions rather than a continually pharmacologically induced effect. The most probable explanation, however, is a persistent effect of the drug per se. This is supported by previous observations in which relatively stable ventricular tachyarrhythmias were abolished by QX-572 and reappeared often after as long as I5 hours (Rydén et al., 1974b). Other quaternary ammonium compounds active against ventricular tachyarrhythmia have also been found to have a long duration of action (Romhilt et al., 1972; Gillis et al., 1973; Kniffen et al., 1974).

\section{Dose and plasma levels}

The efficacy of QX-572 as judged by the incidence of ventricular tachycardia was not related to the absolute amount infused or the plasma levels. Based in part on the present group of patients, poor correlation was found between the amount of drug infused and plasma levels (Rydén et al., 1974a). This suggests that a standardized dosage of $\mathrm{QX}$ 572 could be given rather than $8 \mathrm{mg} / \mathrm{kg}$ body weight; this would have practical advantages.

\section{Possible contraindications}

Patients with atrial flutter and fibrillation were not accepted for this study nor were patients with bundle-branch block. The presence of such abnormalities would have introduced a risk of erroneous differentiation between ventricular premature contractions and aberrantly conducted QRS complexes of supraventricular origin. A clinically important question is whether atrial fibrillation and flutter should contraindicate the use of QX-572. Attempts to control chronic atrial fibrillation by means of QX-572 were not successful (Schwartz et al., 1967). Furthermore QX-572 in the doses used increased conduction velocity through the atrioventricular node (Rydén, Olsson, and Kvasnička, 1975b). Thus, the use of QX-572 may increase the ventricular rate in the presence of these arrhythmias. In the present study no evidence was found of a depressent effect of QX-572 on cardiac conduction. The very few and brief episodes of conduction abnormalities were most likely caused by the disease itself. Until further experience is gained, atrioventricular block of second and third degree should, however, be regarded as contraindications to the drug.

\section{Side-effects}

The initial fall in blood pressure during the infusion is explained by peripheral vasodilatation and can to a large extent be avoided by using a slow rate of infusion (Schwartz et al., 1967; Rydén et al., 1975a). The QX-572 induced increase of heart rate is probably caused by increased sympathetic drive (Rydén et al., 1975b; U. Eliasson and L. Rydén, unpublished data). Whether the same mechanism causes the late increase in blood pressure is not known. At the time when the increase in blood pressure is greatest, about 20 minutes after the completion of QX-572 infusion, the heart rate has largely reverted to the preinfusion level. The changes in heart rate and blood pressure will increase the oxygen demand of the heart (Robinson, 1967; Holmberg, Serzysko, and Varnauskas, 1971). Chest pain was reported as a side-effect by 12 per cent of the patients treated with QX-572 (Table 4) and may be explained by such mechanisms. Chest pain was not recorded as a side-effect in any of the patients in the saline group, though some patients had received analgesic drugs. When a close evaluation of the consumption of analgesics and anti-emetics was performed there was no difference between the two groups (Table 5). The time period o to 3 hours was chosen to cover the period of changes in blood pressure and heart rate after QX-572 infusion. The probable explanation for the lack of records of chest pain and nausea as side-effects in the saline group is the single-blind design. Saline has not been thought to induce such symptoms and they have been interpreted as natural symptoms of the disease. QX-572 can of course not be excluded as the cause of chest pain and nausea but neither, on the other hand, should the possible association be overemphasized.

Using the release of serum aspartate aminotransferase as a measure of the infarction size (Kibe and Nilsson, 1967), no difference was found between patients receiving QX-572 and saline. No cerebral side-effects were observed in the QX-572 group. Since quaternary ammonium compounds do not cross the blood-brain barrier (Goodman and Gilman, 1970), this was not to be expected. Circumoral paraesthesia has in previous studies been experienced by almost all patients receiving QX-572 (Rydén et al., 1975a b). The explanation for the present comparatively low incidence of para- 
esthesia is probably that the patients were informed about this side-effect and not subsequently questioned about its occurrence. QX-572 is a potent local anaesthetic. The paraesthesia parallels the peak level of QX-572 in plasma and is probably explained by local anaesthesia of highly perfused tissues.

\section{QX-572 and lignocaine}

The present study included a comparison of lignocaine and QX-572 on a selected group of patients who all had ventricular tachycardia. The results suggest that the antiarrhythmic efficacy of these drugs is comparable. This is also supported by the fact that of 6 patients with ventricular tachycardia after QX-572, 4 still had runs of ventricular tachycardia after lignocaine. The dose of lignocaine was comparatively high (Harrison and Alderman, 1972) and in some patients the infusion rate had to be reduced, usually because of cerebral side-effects. Thus, it may be argued that a single dose of QX572 has been compared to intensive lignocaine treatment.

\section{Concluding remarks}

QX-572 in the present study proved to be an effective agent against ventricular tachyarrhythmias complicating acute myocardial infarction. The rapid onset of action and long duration together with the lack of cerebral side-effects are advantageous properties. An initial decrease in blood pressure during the infusion of QX-572 can be diminished by a short pause followed by a reduced rate of infusion. The increase in heart rate and late rise of blood pressure are clinically the most important sideeffects. Results from animal experiments suggest that the increase in heart rate, can be modified by the use of beta-blocking agents (U. Eliasson and L. Rydén, unpublished data).

QX-572 is considered to be a valuable supplement to the therapeutic arsenal in the coronary care unit but should at present be used only on strict criteria. The most important of these are probably refractory ventricular arrhythmias.

The authors wish to thank Miss Ylva Winsnes for very skilled assistance with the data collecting and statistical calculations. We are also grateful to the personnel in the coronary care unit for their careful help and unfailing enthusiasm without which this study would never have been possible.

\section{References}

Bruyneel, K. J. J., and Opie, L. H. (1973). The value of warning arrhythmias in the prediction of ventricular fibrillation within one hour of coronary occlusion. Experimental studies in the baboon. American Heart fnurnal, 86, 373.
Covino, B. G., and Rachwall, P. (1964). Comparative cardiac effects of quinidine and $\mathbf{N}, \mathbf{N}$ (phenylcarbamoylmethyl) dimethylammonium chloride (QX-572), a new antiarrhythmic agent. Fournal of New Drugs, 4, 30.

D'Amato, H. E., and Truant, A. P. (1962). Antiarrhythmic activity of a series of quaternary ammonium derivatives of lidocaine (abstract). Federation Proceedings, 21, 127.

Dhurandhar, R. W., MacMillan, R. L., and Brown, K. W. G. (197I). Primary ventricular fibrillation complicating acute myocardial infarction. American fournal of Cardiology, 27, 347.

Gillis, R. A., Levine, F. H., Thibodeaux, H., Raines, A., and Standaert, F. G. (1973). Comparison of methyl lidocaine and lidocaine on arrhythmias produced by coronary occlusion in the dog. Circulation, 47, 697.

Goldman, M. J. (1970). Principles of Clinical Electrocardiography, 7th ed. Lange Medical Publications, Los Altos, California.

Goodman, L. S., and Gilman, A. Z. (1970). The Pharmacological Basis of Therapeutics, 4th ed., p. 536. Macmillan, New York.

Harrison, D. C., and Alderman, E. L. (1972). The pharmacology and clinical use of lidocaine as an antiarrhythmic drug - 1972. Modern Treatment, 9, 139.

Henning, R., and Holmberg, S. (1971). Erfarenheter från Sahlgrenska sjukhusets hjärtinfarktavdelning. Läkartidningen, 68, 3603 .

Holmberg, S., Serzysko, W., and Varnauskas, E. (197I). Coronary circulation during heavy exercise in control subjects and patients with coronary heart disease. Acta Medica Scandinavica, 190, 465.

Katz, R. L. (1964). Antiarrhythmic action of N,N-bis (phenylcarbamoylmethyl) dimethylammonium chloride (QX-572) in cat and dog. Anesthesiology, 25, 291.

Katz, R. L. (1965). Antiarrhythmic and neuromuscular effects of QX-572 in man. Acta Anaesthesiologica Scandinavica, 9, 73 .

Kibe, O., and Nilsson, N. J. (1967). Observations on the diagnostic and prognostic value of some enzyme tests in myocardial infarction. Acta Medica Scandinavica, 182, 597.

Kniffen, F. J., Lomas, T. E., Noble-Allen, N. L., and Lucchesi, B. R. (1974). The comparative antiarrhythmic actions of lidocaine and its quarternary derivative, methyl lidocaine. Circulation, 49, 264.

Lown, B., Vassaux, C., Hood, W. B., Fakhro, A. M., Kaplinsky, E., and Roberge, G. (1967). Unresolved problems in coronary care. American fournal of Cardiology, 20, 494.

Madan, B. R., Khanna, V. K., and Madan, V. (1967). Some local anaesthetics in experimental cardiac arrhythmias. Indian fournal of Physiology and Pharmacology, 11, 45.

Mogensen, L. (1970). Ventricular tachyarrhythmias and lignocaine prophylaxis in acute myocardial infarction. Acta Medica Scandinavica, 188, Suppl. 513.

Norris, R. M., Mercer, C. L., and Yeates, S. E. (1970). Idioventricular rhythm complicating acute myocardial infarction. British Heart fournal, 32, 617.

Robinson, B. F. (1967). Relation of heart rate and systolic blood pressure to the onset of pain in angina pectoris. Circulation, 35, 1073.

Romhilt, D. W., Bloomfield, S. S., Chou, T.-C., and Fowler, N. O. (1973). Unreliability of conventional electrocardiographic monitoring for arrhythmia detection in coronary care units. American fournal of Cardiology, 31, 457.

Romhilt, D. W., Bloomfield, S. S., Lipicky, R. J., Welch, R. M., and Fowler, N. O. (1972). Evaluation of bretylium tosylate for the treatment of premature ventricular contractions. Circulation, 45,800 . 
Rothfeld, E. L., Zucker, I. R., Parsonnet, V., and Alinsonorin, C. A. (1968). Idioventricular rhythm in acute myocardial infarction. Circulation, 37, 203.

Rydén, L., Berlin, A., and Treiber, L. R. (1974a). Plasma concentrations and urinary excretion of the antiarrhythmic quarternary ammonium compound QX-572 in man. European fournal of Clinical Pharmacology. In the press.

Rydén, L., Hjalmarson, Å., Kvasnička, J., and Liander, B. (1975a). Haemodynamic effects of the antiarrhythmic quaternary ammonium compound QX-572 in man. British Heart fournal, 37, 65.

Rydén, L., Hjalmarson, Å., Wasir, H., and Werko, L. (1974b). Effects of a long-acting antiarrhythmic agent - QX-572-on therapy resistant ventricular tachyarrhythmias. British Heart fournal, 36, 81 I.

Rydén, L., Holmberg, S., and Waldenström, A. (1974c). The accuracy of nurses based arrhythmia detection in a coronary care unit. Accepted for the First World Congress on Intensive Care, London.

Rydén, L., Olsson, B., and Kvasnička, J. (1975b). Electrophysiological effects of the antiarrhythmic agent QX-572 in the human heart with special reference to rate-induced changes in effective refractory periods. Cardiovascular Research, 9, 81.

Rydén, L., Waldenström, A., and Holmberg, S. (1974d). The accuracy of intermittent ECG sampling in the arrhythmia detection and evaluation of antiarrhythmic drugs. Accepted for the First World Congress on Intensive Care, London.

Schwartz, M. L., Stapleton, J., and Covino, B. G. (1967). Clinical pharmacology of $\mathrm{N}, \mathrm{N}$-bis (phenylcarbamoylmethyl) dimethylammonium chloride (QX-572). A new antiarrhythmic agent. Fournal of Clinical Pharmacology, 7, 278.

Snedecor, G. W., and Cochran, W. G. (1967). Statistical Methods, 6th ed. The Iowa State University Press, Ames, Iowa.

Siegel, S. (1956). Nonparametric Statistics for the Behavioural Sciences. McGraw-Hill, New York.

Sowton, E., Leatham, A., and Carson, P. (1964). The suppression of arrhythmias by artificial pacemaking. Lancet, 2, 1098.

Swedberg, J., and Malm, A. (1964). Pacemaker stimulation in ventricular paroxysmal tachycardia. Acta Chirurgica Scandinavica, 128, 610.

World Health Organization (1970). Report: Ischaemic Heart Disease Registers (EURO 5010 (4)), pp. 32-33. Copenhagen.

Requests for reprints to Dr. Lars Rydén, Department of Medicine I, Sahlgren's Hospital, S-413 45 Göteborg, Sweden. 